\title{
SAFFIOTI REVISITADA: a atualidade do enfrentamento entre feminismo e capitalismo
}

\author{
Céli Regina Jardim Pinto*
}

\begin{abstract}
O artigo parte das teses do livro de Heleieth Saffioti "A Mulher na Sociedade de Classes" analisando a centralidade do capitalismo na opressão das mulheres e suas consequências na produção teórica feminista que defende a superação do capitalismo como essencial para a sua libertação. Está divido em quatro partes: na primeira expõe as teses de Saffioti informadas por um marxismo ortodoxo que não reconhece a luta feminista; na segunda, discute o encontro entre o marxismo e o feminismo na década de 1980; na terceira parte discute algumas teses de Nancy Fraser, mostrando sua trajetória de uma postura eclética a uma neomarxista; finalmente, na ultima parte, as questões discutidas nas três primeiras são trabalhadas de uma perspectiva pós estruturalista.

Palavras-Chave: Saffioti. Classes sociais. Mulheres. Feminismo. Trabalho feminino.
\end{abstract}

\section{INTRODUÇÃO}

A opressão das mulheres ${ }^{1}$ e a história do capitalismo, tanto em sua versão imperialista, como nas suas franjas coloniais e pós-coloniais, têm uma relação constitutiva. Não há possibilidade da superação da opressão das mulheres dentro do capitalismo - pelo menos das mulheres das classes populares, que junto com os homens são partes fundamentais para a reprodução do sistema. Daí que só as mulheres da burguesia teriam possibilidades de se libertar no interior do capitalismo. Tal forma de expor o problema, entretanto, encobre uma gama de questões centrais a serem consideradas. Em primeiro lugar, a atual estrutura de classes do capitalismo é muito mais complexa do que o binômio burguesia-proletariado. Além dos vastos setores aninhados sob o guarda-chuva da classe média, as classes populares, muito

* Universidade Federal do Rio Grande do Sul (UFRGS). Av Bento Gonçalves 9500. Porto Alegre - Rio Grande do Sul-Brasil.celirjp@gmail.com

https://orcid.org/0000-0003-1067-655X

${ }^{1}$ Somente usarei os substantivos mulher e homem no singular quando se tratar de citação ou referência direta a texto de autora que assim o faz. por conta das novas formas que o trabalho tomou, não podem mais serem pensadas a partir da categoria marxista de proletariado.

Mas, para além do pertencimento de classe, existem outros fatores de opressão, que estão inscritos no próprio corpo das mulheres: a raça, a etnia, a cidadania (ou sua falta), a orientação sexual, a falta de direitos civis e políticos em muitos países, as dificuldades de entrar no mundo da política (mesmo onde lhes é assegurado este direito constitucionalmente), o assédio e a violência sexual. Nenhuma destas opressões se explicam como essenciais para o capitalismo.

As formas de dominação não são comuns a todas as mulheres e variam conforme o pertencimento: ser da classe operária, ser burguesa, ser negra, ser indígena, ser lésbica, ser trans, ser do norte ou do sul global, referem-se a condições que perfazem formas distintas de opressão, que apontam para as relações de poder entre as classes, as raças, as orientações sexuais, entre outros marcadores. Apesar da centralidade do capitalismo na estrutura de dominação, a condição de opressão das mulheres é anterior: tem configurações independentes 
dele e, somando-se a isto, não há razões para pensar que em experiências não-capitalistas a opressão sobre as mulheres perde o sentido.

Tendo um tempo de longa duração, anterior e posterior ao capitalismo, a historia da opressão sobre as mulheres não pode ser restrita à história do modo de produção. Mas também é preciso estar atenta ao fato de que esta opressão não faz parte da natureza humana, nem tampouco a exclusão das mulheres em todas as suas formas é essencial ao capitalismo. Houve e há conquistas do movimento de mulheres e do feminismo no interior do sistema capitalista. É difícil manter o argumento de que nos últimos 100 anos, por exemplo, as condições das mulheres de diferentes classes, raças, etnias, orientações sexuais não tenham experimentado mudanças positivas, por força inclusive do movimento feminista em suas múltiplas variáveis. ${ }^{2}$ Mesmo assim, não se pode deixar de considerar que o capitalismo em suas diferentes fases tem tido força para frear conquistas ou pelo menos ameaça-las de forma bastante contundente.

No decorrer da segunda década do século XXI e principalmente nos seus últimos cinco anos, o mundo tem assistido a uma acelerada guinada em direção à construção de uma hegemonia política da extrema direita, que tem como liderança máxima a presidência de Donald Trump nos Estado Unidos, mas que se espalha por partidos políticos e por governos จิ como o da Hungria, da Turquia, das Filipinas e o do Brasil, só para citar os mais emblemáticos. ठे Estas novas experiências de extrema direita ช no mundo trazem algo de original em relação $\underset{I}{+}$ aos golpes de estado, tanto na América Latina, ¿. como fora dela, no século passado: estão sendo ले construídas por governos eleitos democratica-

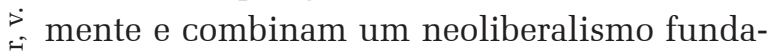

¿ 2 Contrariando a tendência hegemônica do século 21, ส manterei movimento feminista no singular. Isto não en- volve não reconhecer a multiplicidade de feminismos,

If muitos inclusive em rota de colisão, mas sim reafirmar,

ઉ acadêmica e politicamente a existência da categoria femi-

nismo. Há um conjunto de manifestações socias lideradas

por mulheres que tem um núcleo comum: que encontram

na condição de ser mulheres em relação a condição de ser

homens a causa de sua opressão. mentalista com uma pauta ultraconservadora que atinge os costumes, os direitos humanos, as artes e a educação. E, neste cenário, o capitalismo, para se reproduzir, necessita bater de frente com o movimento feminista e suas conquistas. É o momento, portanto, de voltar a perguntar-se: qual é trama que coloca em lados opostos a luta feminista e o capitalismo? Por que o capitalismo, já quase entrando na terceira década do século XXI, necessita de uma família heterossexual, de valores cristãos, de uma moral reacionária, de mulheres voltadas para a casa, dementes ao marido?

Neste quadro, o livro de Heleieth Saffioti, "A Mulher na sociedade de Classes: Mito e Realidade" (2013) tem uma atualidade particular. E este artigo, que ora introduzo, objetiva refletir sobre esta conflagrada relação entre a opressão das mulheres e o capitalismo, tomando o texto de Saffioti como ponto de partida e percorrendo alguns textos posteriores que tratam desta mesma relação. Dado o longo período de tempo percorrido desde a escrita de Saffioti e o peso da produção teórica feminista das últimas cinco décadas, foi necessário fazer uma rigorosa seleção quanto ao período a ser analisado, às autoras e à própria problemática. Em relação ao tempo, o artigo trabalhará com dois momentos bem específicos: o inicio dos anos de 1980, quando houve uma produção muito qualificada, que discutiu a relação entre feminismo e marxismo; e o momento atual, de fim da segunda década do século 21, pelas especificidades do capitalismo, que têm provocado fortes ataques às conquistas das mulheres nos últimos 50 anos. No que concerne às autoras, escolhi quatro ícones da discussão: três que escreveram na década de 1980 e uma que tem sido uma voz muito proeminente no século 21; são elas respectivamente, Michelle Barrett, Heidi Hartmann, Sandra Harding e Nancy Fraser.

Ainda neste momento introdutório, é necessário esclarecer que houve uma escolha de não incluir a discussão das feministas teóricas descoloniais e entre elas, mormente, as teóricas do feminismo negro. Este é um amplo 
campo que na América Latina estabelece uma original releitura do marxismo terceiro-mundista das décadas de 1960/70. Avançando para além desta atualização, redesenham o mapa da luta feminista e anticapitalista a partir de um novo ponto de vista da geografia política, onde as questões do império, do colonial e da diáspora negra adquirem uma robustez teórica que rompe que a própria episteme de um marxismo oitocentista ou de um feminismo ocidental branco e produzido no norte global. Entretanto, no limite do que me propus neste artigo, a incorporação destas perspectivas me levaria a outras questões que não a específica relação entre o trinômio: capitalismo - opressão das mulheres - feminismo. ${ }^{3}$

Dividirei o artigo em quatro pequenas partes: na primeira exporei as principais teses de Heleieth Saffioti, cujo foco se limitará à sua perspectiva teórica; ${ }^{4}$ na segunda, trabalharei com a produção internacional sobre capitalismo e opressão com os textos do início da década de 1980, quando esta questão estava muito presente na produção de acadêmicas feministas; na terceira parte, analisarei a produção mais recente e talvez mais militante de Nancy Fraser e suas co-autoras que fazem um releitura importante da relação entre opressão das mulheres e capitalismo na sua atual fase imperial neoliberal. Não se trata de uma análise comparativa ou da busca de um processo evolutivo do conhecimento sobre a relação entre capitalismo versus opressão das mulheres, mas de uma investigação em textos clássicos da teoria feminista, buscando um enquadramento teórico para entender o atual momento. Na quarta parte, tratarei de fazer uma reflexão sobre a atual fase da relação entre feminismo e capitalismo incorporando alguns aspectos da teoria pós estruturalista.

${ }^{3}$ Para a discussão sobre feminismos pós coloniais, decoloniais ver o compreensivo artigo de Luciana Ballestrin (2017)

${ }^{4} \mathrm{O}$ livro de Heleith Saffioti está dividido em 3 partes. Neste artigo será trabalhada apenas a primeira parte, quando

\section{CAPITALISMO, DOMINAÇÃO E MARXISMO EM SAFFIOTI}

Já na introdução de seu livro, Heleieith Saffioti deixa claro sua filiação ao que chama de socialismo científico, afirmando que fará uma análise onde hierarquiza classe e sexo, tomando o último como status. Em suas palavras, o trabalho busca:

Romper com o raciocínio analógico que atribui às
categorias de sexo características semelhantes à
aquelas presentes nas classes sociais, procurando-
se desvendar, na elaboração social do fator sexo,
os requisitos estruturais e funcionais do sistema
capitalista de produção e os mecanismos de sua
satisfação (Saffioti, 2013, p. 45).

Ainda na introdução, a autora afirma que só a consciência do proletariado encontrará solução para os problemas de dominação postos pelo capitalismo (Saffioti, 2013, p.48). A importância do trabalho de Saffioti está exatamente em reconhecer uma condição própria das mulheres na estrutura de classe, mesmo não atribuindo a elas ou às suas lutas qualquer autonomia, independente da luta do proletariado. Não foi tarefa fácil para uma acadêmica marxista, na década de 1960, tratar de um agente social - as mulheres - que não tinha lugar no construto teórico. ${ }^{5}$

Neste sentido, Saffioti advoga que, ao contrário do que o senso comum afirma, o capitalismo não integrou as mulheres ao mercado de trabalho, mas as alijou deste espaço, apontando que as mulheres sempre trabalharam nas sociedades pré-capitalistas. Segundo ela, o capitalismo lança mão da tradição da supremacia masculina para expulsar as mulheres (Saffioti, 2013, p.66) e chama esta tradição de superestrutura, mas não explica, ao longo de sua obra, dois aspectos centrais: em que se calca a su-

5 Talvez seja por isto que Heleieth Saffioti é tão enfática em uma nota preliminar da $1^{\mathrm{a}}$ edição de seu livro em dizer que o livro não tinha sido escrito para as mulheres, não defendia o sexo feminino e portanto não era feminista. Quem, como eu, conheceu e privou com Heleieth nas décadas de 1980 e 90 e 2000, sabe o quanto está mulher lutou pelos direitos das mulheres e o quanto foi uma aguerrida feminista. 
premacia masculina; e como em um esquema tão dogmaticamente marxista, a superestrutura define a estrutura, e não o contrário.

Como Saffioti não admite relações de poder que se exerçam independente da relação das classes, o que fica claro ao longo do seu texto, não consegue explicar esta posição de submissão das mulheres a não ser como tradição, ou mesmo como natureza. Pela mesma razão, não reconhece que entre homens e mulheres da classe proletária existam relações de poder e por isso identifica a "hostilidade dos homens [proletários] ao trabalho feminino como falsa consciência” (Saffioti, 2013, p.76). No construto de Saffioti, há um peso essencial sobre uma natureza das mulheres, atribuida à maternidade, com consequências na vida social, como a necessidade de se ausentarem do trabalho devido às suas tarefas de cuidar dos doentes e inclusive do marido. No texto, há uma constante tensão entre mulheres - capitalismo - inserção no mercado de trabalho. E nesta tensão se reforça a ideia da naturalização da condição das mulheres: "a sociedade de classes não oferece à mulher um quadro de referência através do qual suas funções possam ser avaliadas e integradas" (Saffioti, 2013, p. 96-97).

A presença desta naturalização fica mais explicita quando Saffioti aponta uma dualidade própria à mulher: "a sua necessidade de integração na estrutura de classes (atividades profissionais) e sua necessidade de se "dar จิ à família” (Saffioti, 2013, p.97). Aqui aparece o - grande nó teórico no qual a interpretação mar\&े xista embreta Saffioti: ela trabalha com mulhe¿ res que não se integram na estrutura de classe

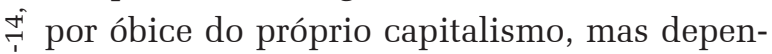
¿. dem da luta de classes (na qual não estão inले seridas) para galgarem a libertação. Ao mesmo $\vec{t}$ tempo, naturaliza a condição das mulheres através da maternidade e da relação essencial com a família, que parece não estar definida por sua contraditória condição de classe.

Segundo seu esquema analitico, o capitalismo força a segunda em detrimento da primeira quando deveria haver um equilíbrio:
"Qualquer hierarquização das funções femininas nas sociedades capitalistas reforça as dificuldades de integração da mulher na sociedade" (Saffioti, 2013, p.97). Assim, a posição subalterna das mulheres no capitalismo provoca o seu desemprego, sua marginalização na estrutura de classe e o reforço do "complexo de masculinidade", associado ao homem como provedor, e a "mística feminina", isto é, as mulheres no lar. Segundo Saffioti, o capitalismo se utiliza de valores anteriores a ele para alijar a mulheres do mercado de trabalho. Mesmo reconhecendo, repetidas vezes, a existencia da condição subalterna das mulheres antes do capitalismo, Saffioti é enfática em afirmar que entre os problemas "gerados pelas sociedades capitalista" está o da mulher (Saffioti, 2013, p 111), que tanto quanto se pode intuir, é o problema do desemprego, ou do emprego em condições inferiores aos homens.

Após caracterizar a condição da mulheres na sociedade capitalista, Saffioti busca a solução socialista para a questão. Nesse ponto, é muito forte sua rejeição a qualquer movimento feminista ou luta autônoma das mulheres, entendendo que a libertação das mulheres é uma decorrência da luta de classes. Mesmo assim, sofistica sua análise mostrando que há um certo grau de independência em relação ao que chama de fator natural do sexo:

Assim, as categorias de idade, como as de sexo, não
apresentando autonomia socioeconômica e cultu-
rale inserindo-se nas totalidades parciais (classes
sociais) de que se compõe a sociedade, são não
apenas coletividades diversas das classes sociais,
como também mantem entre si relações de nature-
za diferentes da daquelas que caracterizam a ação
recíproca de coletividades que ocupam posições an-
tagônicas na estrutura social (Saffioti, 2013, p.122).

Mesmo pontuando a falta de autonomia socioeconômica e cultural, a autora enfatiza que estas categorias mantêm relações que não se esgotam nas suas condições de classe. Este é um dos seus mais interessantes achados, tendo em vista a perspectiva teórica que adota: antes de tudo, Saffioti reconhece que dentro do ca- 
pitalismo as condições dos homens e das mulheres são distintas. Mas também reconhece a existencia de contradições que não se resumem às de classe, entendendo que seu limite está em identificar estas relações, não como a verificação da complexidade da luta pela superação do capitalismo, mas como um limitador: "quando o domínio se exerce em várias categorias sociais que se cruzam, as contradições mais agudas da sociedade podem enfraquecer-se momentaneamente" (Saffioti, 2013, p.123). Este seria o caso do domínio dos homens sobre as mulheres nas classes dominadas, impedindo que eles lutem pela integração econômica das mulheres e, não o fazendo, contribuem para os interesses da classe dominante.

Incorporando as premissas mais fundantes do marxismo, como infraestrutura e superestrutura, e assimilando as consequências do economicismo que adota, Saffioti avança na compreensão da condição de duplamente dominadas das mulheres, quando identifica que o sistema capitalista explora de forma diversa a ambos os sexos. Como já apontamos, divide o espaço das mulheres de duas formas: a primeira, que chama de natural, de funções naturais; e a segunda, que chama de trabalhadora doméstica e socializadora dos filhos. São estas duas funções que segundo Saffioti (2013, p.127) provocam o "alijamento do elemento feminino da estrutura de classes".

Ao discutir as formas de libertação das mulheres destas duas condições através da possibilidade de impedir a gravidez involuntária e da educação das crianças em creches (que chama de infantários) ao mesmo tempo, se pergunta se o sistema capitalista teria potencial para assimilar toda esta nova força de trabalho que chegaria ao mercado. Saffioti é bastante cética sobre esta possibilidade no capitalismo e vai mais além, afirmando que mesmo que a integração das mulheres no mercado de trabalho se realize, como aconteceu em econômicas coletivizadas, isto não envolveu a liberação total das mulheres. O achado de Saffioti é muito significativo:

\begin{abstract}
Seria ilusório, entretanto, imaginar que a mera emancipação econômica da mulher fosse suficiente para libertá-la de todos os preconceitos que a discriminam socialmente. A realizações histórica da sociedade de economia coletiva tem mostrado que embora a emancipação econômica da mulher seja condição sine qua non de sua total libertação, não constitui, em si mesma, esta libertação integral (Saffioti, 2013,p.128).
\end{abstract}

Ao longo de todo o seu texto, percebe-se uma constante tensão no argumento da autora, pois, ao tempo em que atribui ao capitalismo a opressão feminina e a falsa consciência dos homens das classes dominadas, reconhece a condição de dominação anterior e posterior ao capitalismo, mas não consegue explicar estas relações de poder, que extrapolam seu esquema de análise. Na verdade, o complicador maior é que Saffioti não identifica a condição das mulheres como decorrência da dominação masculina, mas da dominação do sistema capitalista. Quando discorre sobre a dificuldade da China e da URSS de acabar com a prostituição, aponta a dificuldade da "recuperaçãoe integração social da prostituta” (Saffioti, 2013,p.130), não discutindo a manutenção do comércio sexual onde os homens são os grandes compradores. Esta ausencia da identificação dos homens como elementos constitutivos da dominação fica ainda mais clara quando Saffioti, muito apropriadamente, identifica as diferenças entre mulheres de classes distintas. Aponta que homens e mulheres das classes dominantes exploram o trabalho de homens e mulheres das classes dominadas, mas também enfatiza que a relação entre homens e mulheres varia de acordo com as classes. Para ela, os interesses de homens e mulheres burguesas não levam à dominação de um sobre o outro, mas à solidariedade. Já na classe trabalhadora, "a solidariedade é as vezes turvada por uma semi concorrência entre os sexos" (Saffioti, 2013, p.133).

Saffioti encerra a primeira parte de seu livro, focalizado neste artigo, com o título de "A solução feminista". A autora é uma ferrenha crítica ao que denomina de feminismo autô- 
nomo e defende a subordinação da luta das mulheres à luta proletária, entendendo que a autonomia conservaria a estrutura de classes, e manteria uma visão equivocada da sociedade burguesa; conclui, afirmando que se o "o feminismo socialista não liberou completamente a mulheres é porque não atingiu sua maturidade" (Saffioti, 2013, p.195). A discussão trazida na tese de Saffioti foi inaugural, mesmo que não se identifique como feminista e não atribua à relação com os homens a questão da dominação das mulheres, mas ao sistema capitalista tout cour. O que nos disse Saffioti é que o capitalismo tinha sexo e isto era fundamental para sua reprodução. Entretanto, transita entre categorizar as mulheres como um sujeito particular, quando fala da sua não integração ao mercado de trabalho e, quando a subordina ao proletariado, à sua natureza de sujeito unicamente de classe.

Seu texto é datado por um marxismo latino-americano ortodoxo e muito informado pelo Partido Comunista Brasileiro e suas estreitas relações com a União Soviética, daí que na sua análise a opressão sobre as mulheres nasce como um cogumelo com o capitalismo e deve desaparecer com o amadurecimento do socialismo.6 Mas Heleieth Saffioti escreveu este livro na segunda metade da década de 1960 e o publicou em 1969. Hoje, após 50 anos de sua publicação, quando o mundo enfrenta o avanço de um capitalismo neoliberal radical com จิ políticas explícitas contrárias às conquistas $\because$ das mulheres, no qual há um forte ataque ao \&े feminismo e uma defesa da chamada família \& tradicional, eufemisticamente designada como

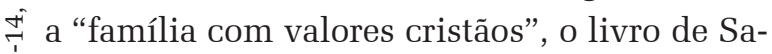
$\dot{2}$ ffioti merece cuidadosas releituras.

${ }^{6}$ Não se está a afirmar que Heleieth Saffioti pertencia ao Partido Comunista, ou mesmo que se declarasse comunista, isto é tema para suas biógrafas, massim que na época em que escreveu o livro, no Brasil havia uma grande influência sobre quase toda a esquerda de um marxismo muito ortodoxo com grande liderança do PCB e influência da URSS.

\section{O FEMINISMO E O MARXISMO NO NORTE}

Uma produção teórica do feminismo internacional associada ao marxismo vai aparecer quase uma década após a publicação do livro de Saffioti,7 quando novamente o marxismo adquire um largo espaço, tanto como alvo de crítica, quanto como proposta de análise e de estratégia de luta contra a opressão das mulheres. O movimento feminista que cresce, principalmente na Europa e nos Estados Unidos na década de 1970, havia provocado fortes reações contrárias na esquerda marxista, que o via como um desvio na luta pelo socialismo.8 Tendo este cenário como pano de fundo, as feministas acadêmicas reagem no início da década de 1980, como abordaremos adiante.

Tomarei textos clássicos desta discussão que foram publicados nos anos de 1980/81. São os textos de Michèlle Barret, de Heidi Hartmann e Sandra Harding, os quais diferem de Saffioti por uma declarada filiação feminista, mesmo partihando com ela a centralidade do marxismo, em versões muito críticas. Estas mulheres não são latino americanas, não têm como ponto de partida um marxismo latino americano nem a vivência não democrática do subcontinente. Barrett é inglesa, Hartmann e Harding são estadunidenses. A primeira está centrada em discutir a relação entre feminismo e marxismo e, ao contrário de Saffioti, reconhece o feminismo como uma teoria e uma luta independente, que se relaciona com o marxismo e a luta de classes, mas que não pode ser confundido como eles. Desenvolve seu argumento a partir de três questões básicas: 1. o conceito de patriarcado como a-histórico e que não dá conta da opressão da mulheres; 2. o capitalismo, que não constitui a causa da opressão, pois, ele existe antes e se mantém

${ }^{7}$ O livro de Saffioti foi citado por Iris Young em um texto publicado em 1981, já em sua versão em inglês (Young, 1981)

${ }^{8}$ Isto também acontecia no Brasil que vivia sob uma ditadura militar. A militância feminista era mal vista pela esquerda que a via como um desvio da luta d classe e da luta pela redemocratização (Pinto, 2003). 
após; 3.o capitalismo, como se apropriando, através da divisão do trabalho, da opressão da mulher a seu favor. Aponta para uma insolúvel disputa entre o marxismo e o feminismo a respeito do que deve ter a supremacia analítica: o gênero ou as classes. (Barrett, 1980, p. 29).

Argumentando que a opressão das mulheres não é uma necessidade do capitalismo, ao contrário de Saffioti, Barrett aponta a tese geralmente defendida, segundo ela, com base no trabalho não remunerado das mulheres. $\mathrm{O}$ que é necessário para o sistema é uma ideologia sobre a produção e reprodução das categorias de feminino e masculino, entendendo que nestas estão embuídas as opressões, que adquirem base material na produção e reprodução do capitalismo. E afirma textualmente:

O que necessitamos analisar são precisamente os mecanismos através dos quais a opressão das mulheres é assegurada em diferentes contextos, desde que somente assim, poderemos confrontar o problema de como mudá-lo (Barrett, 1980, p.250). ${ }^{9}$

Indagando se o capitalismo trouxe vantagens para as mulheres, ao contrário de Saffioti, Barrett (1980) não nega as transformações positivas. Mas enfatiza que o capitalismo não tem condições de realizar três transformações necessárias à libertação das mulheres: redivisão do trabalho e das responsabilidades com o cuidado das crianças; fim da dependência das mulheres do salário dos maridos; e a transformação da ideologia de gênero que conforma o feminino e o masculino. Entretanto, reconhece que a expansão do capitalismo aumentou a possibilidade de empregos para as mulheres e que houve políticas de contracepção e de aborto favoráveis a elas. Porém, é bastante enfática em afirmar que estas transformações atingiram as mulheres de forma distinta conforme suas classes sociais. As mulheres burguesas experimentaram grandes mudanças em relação aos diretos civis, ao direito à propriedade, ao próprio trabalho, mas ao mesmo tempo enfatiza:

${ }^{9}$ Os textos de Barret, Hartmann e Harding estão orginalmente em inglês e foram livremente traduzidos por mim para uso exclusivo neste artigo.
"É talvez menos claro que mudanças podemos esperar no caso das mulheres da classe trabalhadora" (Barrett, 1980, p.255).

Mesmo admitindo que o capitalismo não tem possibilidade de garantir as condições para a libertação das mulheres, Barrett conclui seu livro com a defesa da autonomia do movimento feminista em relação ao movimento de esquerda em geral. Segundo ela, não há razões para se pensar que programas socialistas automaticamente defenderiam a liberação das mulheres, mas mesmo assim afirma:

Existe entretanto, imperativos políticos fundamentais nos dirigindo para uma forte presença na esquerda mas na direção de alguma forma de aliança entre o movimento de liberação das mulheres e a esquerda (Barrett, 1980, p.257).

A segunda autora citada, Heidi Hartmann, escreve o artigo principal do clássico The Unhappy Marriage of Marxism and Feminism (Sargent, 1981), advogando que as categorias do marxismo são cegas em relação ao sexo e propondo uma nova forma de análise marxista do feminismo. Ao contrário de Saffioti e Barrett, assume o conceito de patriarcado, apontando que "provoca uma ideologia sexista que o capitalismo acentua”. Seu texto incorpora o conceito, tratando de mostrar que não é a-histórico e universal, como visto por suas críticas. Textualmente afirma:

[...] .então o patriarcado é hierárquico, e homens de diferentes classes, raças ou grupo étnicos tem diferentes espaços no patriarcado, eles são também unidos em suas compartilhadas relações de dominação sobre suas mulheres; eles são mutuamente dependentes para manter esta dominação (Hartmann,1981, p. 15)

Esta autora enfatiza que as bases materiais desta dominação ocorrem através do controle da força de trabalho das mulheres e afirma que não existe "capitalismo puro", como não existe "patriarcado puro", mas um capitalismo patriarcal. Para reforçar a analise do processo de acumulação, segundo ela, é necessário uma ideologia de raça e gênero. Mesmo assim, afir- 
ma que, em um certo momento, o capitalismo pode necessitar exatamente do contrário, da força de trabalho das mulheres e, neste contexto, o patriarcado seria inviável. Ao prosseguir seu argumento, faz uma inflexão muito significativa quando diz não acreditar que o capital tenha força para desestruturar a família patriarcal. E, neste momento, estabelece o divórcio entre o marxismo e o feminismo, pois, coloca o patriarcado como uma relação de dominação que é mais enraizada que o modo de produção, rompendo, desta forma, com a clássica imagem da infraestrutura/superestrutura. Para Hartmann, a luta do feminismo e a luta de classes devem estar separadas, ou a primeira está subsumida à segunda (Hartmann,1981, p.32). Afirma que "Não nega a necessidade da luta pelo socialismo e não vê a liberação das mulheres fora dele, mas que a análise do patriarcado é essencial para a definição do tipo de socialismo que serve às mulheres" (Hartmann,1981, p.32). Encerra seu texto apontando que há necessidade de alianças, mas que as mulheres não podem confiar que um socialismo construído por homens vá garantir, uma vez implantado, a igualdade das mulheres.

Umas das mais destacadas comentaristas de Hartmann é Sandra Harding. Sua postura afasta qualquer possibilidade de casamento entre o marxismo e o feminismo, visto que não imagina a liberação das mulheres se as instituições forem controladas por homens, inปิ dependentes do regime. Faz quatro perguntas o- para enfatizar seu argumento: pergunta porque todas as instituições, inclusive, as socialistas, são dominadas por homens; se o marxismo İ tem resposta para a primeira questão; se o pen¿. samento marxista é capaz de convencer os hoळ mens a deixarem voluntariamente o poder e, finalmente, se existe papel revolucionário para os homens (Harding, 1981, p.138).

Afirmando que o marxismo não tem resposta para questões que envolvem sexo, Harding põe a ênfase na família como a reprodutora essencial para o capital, mas não consegue explicar toda a presença da família nas relações de poder que extrapolam a questão econômica. A família configura um produto que tem reflexos nas relações de trabalho tanto remuneradas como domésticas. Ao mesmo tempo, também naturaliza papéis, tornando os homens e a mulheres "universais" não questionáveis. A família se torna natureza e não cultura:

\footnotetext{
Nós precisamos ao mesmo tempo nos tornarmos nós próprias e criar outras pessoas que serão o novo povo. Para fazer isto nós necessitamos entender e mudar as condições históricas materiais sob as quais pessoas são produzidas na forma capitalista do patriarcado ( Harding, 1981, p.154).
}

Harding busca no que chama de uma teoria psicológica materialista os elementos para mudar as condições de dominação instauradas na família. Com base em Chodorow e Flax, argumenta que é possível construir uma teoria mais poderosa sobre a vida social que extrapole a questão econômica e busque entender como pessoas são formadas em diferentes momentos históricos no interior da família e como esta família nuclear organiza este ser humano, para vivenciar o capitalismo patriarcal. O artigo citado a seguir, termina apontando para a necessidade de se criar esta nova pessoa capaz de romper com as relações de dominação que constituem o patriarcado e o capitalismo e que organizam múltiplas relações na sociedade:

\begin{abstract}
[...] então mulheres necessitam tomar a liderança não somente lutar contra o patriarcado, mas também na luta contra os interesses subjacentes que os homens têm de controlar ambos o patriarcado e o capital e perpetuando relações de dominação através de vários tipos de relações opressivas com os outros. Nós estamos em um momento na história, quando as mulheres necessitam tomar a liderança de criar a teoria e prática que sejam verdadeiramente científicas e nisto elas são mais compreensivamente históricas e materialistas. Mulheres são agora o grupo revolucionário da história (Harding, 1981, p.159).
\end{abstract}

Não é a intenção deste artigo fazer uma análise crítica das teses de Harding, mas pontuar que mesmo sem explicar como este processo de libertação vai ocorrer, ela aprofunda a compreensão das formas de dominação, não 
as reduzindo ao capitalismo, nem mesmo ao patriarcado. É importante pontuar que ela não se filia a um feminismo radical que reduz a dominação ao patriarcado, mas sem dúvida afasta a possibilidade da superação do capitalismo sem a luta feminista. Se compararmos a perspectiva de Saffioti com as três autoras, é possível identificar diferenças importantes.

Saffioti caracteriza a questão das mulheres como uma questão do capitalismo, apontando que ele necessita da dominação sobre a elas para se reproduzir. As demais também trabalham com a relação entre capitalismo e dominação da mulheres, mas introduzem pelo menos quatro questões em comparação à socióloga brasileira: (1) o processo de dominação atinge um espectro mais vasto do que o econômico; (2) ao lado do capitalismo aparece o patriarcado, que se reconfigura no regime,mas tem existência independente; (3) em decorrência disto, a luta pela libertação da mulheres não pode se confundir com a luta contra o capitalismo; (4) o socialismo não garante o fim do patriarcado. Assim, o marxismo de Saffioti não permite que identifique o homem como opressor, mas apenas a classe. Ela, ao contrário das três outras teóricas feministas, não admitia um movimento/luta que tivesse identidade própria, mesmo em um processo de alianças.

Escrevendo seu trabalho, como já sabemos, na década de 1960, estava presente nesta época um sujeito histórico que perde a centralidade, mesmo nos textos marxistas, que é o proletariado. Um conjunto complexo de variáveis colabora para que se entenda com mais precisão esta saída de cena. Três delas são particularmente importantes: a) as transformações nas condições de trabalho, dadas tanto pelas crises e reordenamentos do sistema capitalista, como pelas novas tecnologias que diminuíram fragorosamente a importância do trabalho fabril, precarizando o trabalho tour cour; b) a reação deste “proletariado", bastante distante da prevista por marxistas clássicos; c) o surgimento de novos sujeitos que entram na arena da luta contra o sexismo, o machismo, o racismo, a homofobia.
A ideia de que existe uma fragmentação contida nestes novos sujeitos é um equívoco teórico e analítico. Não há uma fragmentação da luta do proletariado, mas a multiplicação de lutas e o fato destas lutas variadas não serem obrigatoriamente anticapitalistas, o que ainda complica mais o cenário. Esta última variável atinge muito de frente o feminismo, porque no seu interior agrandou-se um feminismo liberal nos países do Norte, que por razões óbvias não incorporou classe, etnia, raça, orientação sexual, e experiências culturais históricas, distintas do chamado ocidente judaico-cristão.

\section{A PERSPECTIVA DE NANCY FRASER}

As feministas próximas ao marxismo, ao neomarxismo e até mesmo ao chamado pensamento pós estruturalista nunca se afastaram da crítica e da proposta de superação do capitalismo, mas trataram de identificar novos sujeitos, novas lutas e antagonismos. A obra de Nancy Fraser é particularmente importante neste cenário, por ter presente a problemática da superação do capitalismo e sempre incorporar questões de classe, raça e gênero, desde sua famosa polêmica com Axel Honneth (2003), ${ }^{10}$ até seus últimos trabalhos em 2019, sobre a crise do capitalismo neoliberal, passando pelo Manifesto Feminista que escreveu em parceria com duas outras autoras.

Fraser constrói sua tese a partir dos dois paradigmas: o da redistribuição e o do reconhecimento, cada um expressando formas distintas de injustiça. Identifica neles quatro diferenças que chama de chaves: o paradigma da distribuição foca (1) em injustiças socioeconômicas, como exploração do trabalho; (2) em uma solução que deriva de alguma forma de reestruturação econômica; (3) em sujeitos coletivos, concebidos como alvo de injustiças, são as classes sociais definidas por sua rela-

${ }^{10}$ Há um texto anterior de Nancy Fraser (1997) onde ela já esboça sua teoria, mas é na polêmica com Honneth que suas teses estão mais amadurecidas 
ção no mercado ou nos meios de produção; (4) na existência das classes como injustas que devem ser abolidas. Já o paradigma do reconhecimento foca: (1) em injustiças vistas como culturais "enraizadas em padrões de representação, interpretação e comunicação”; (2) na solução para estas injustiças através de transformações simbólicas e culturais; (3) nas injustiças sofridas ou derivadas da falta de reconhecimento, falta de respeito, de prestígio de um grupo em relação a outros; (4) no fato de que as identidades, mesmo não sendo essenciais e positivas aprioristicamente, não são eliminadas obrigatoriamente como identidades, pela justiça (Fraser, 2003, p.13).

Em relação a esta quarta diferença do paradigma do reconhecimento, Fraser levanta um ponto importante para a teoria feminista. Afirma que as identidades estão construídas para serem exploradas, e a luta deve ser por sua eliminação. Mas de forma distinta, os grupos que pré existem à injustiça devem ser valorizados como forma de justiça e não eliminados. Pode-se pensar como exemplo do primeiro grupo, os imigrantes, nos países europeus na atualidade; e como segundo, as comunidades dos povos originários no continente americano. Estes grupos, entretanto, não são estanques, alguns são subordinados nas duas dimensões, tanto por sua exclusão econômica, como pelo falta de reconhecimento:

Gênero, eu considero, é uma diferenciação social duo dimensional. Não simplesmente a classe nem simplesmente um grupo, gênero é uma categoria híbrida enraizada simultaneamente na estrutura econômica e na ordem do status social. Entender e recolocar a injustiça de gênero, portanto, requer atendimento de redistribuição e de reconhecimento (Fraser, 2003, p.19).

A perspectiva de Fraser problematiza em uma outra ordem a questão de gênero e da opressão das mulheres. Compartilha com todas as marxistas a identificação das condições subalternas das mulheres na divisão sexual do trabalho no capitalismo. Mas a a sua superação não esgota a injustiça, pois a condição de dominação também é sobre-determinada por questões de reconhecimento, como desprestígio e falta de respeito. Desse modo, para que se supere estas condições de injustiça, Fraser advoga uma paridade de participação, onde todos os adultos interajam como pares, em igualdade de condições tanto materiais (condições objetivas); como de igualdade de respeito por todos os participantes (condições intersubjetivas).

Desenvolvendo a tese de que esta dualidade de injustiças não é exceção entre os sujeitos dominados, Fraser a considera como regra, citando a questão de raça, dos gays e lésbicas, entre outros. Para os propósitos do presente artigo, me limitarei à questão de gênero, entendendo que é fácil perceber a distância entre Fraser e as autoras anteriores: na sua obra não aparece luta proletária, ideologia ou patriarcado. Mas há uma forte presença da noção de desigualdade que conforma as injustiças, tanto econômicas, como as relacionadas como o respeito. Atribui às primeiras a posição dos sujeitos nas relações de produção e na divisão sexual do trabalho. Mas, ao introduzir o conceito de participação paritária, incorpora a questão política, atribuindo a desigualdade no respeito como uma relação de poder, que impede a participação política e mesmo a democracia (Fraser, 2003).

Certamente provocada pelas manifestações de 2011 nos Estados Unidos e a eleição de Donald Trump em 2016, Nancy Fraser dá uma radical guinada em sua reflexão sobre a teoria crítica e a teoria feminista e escreve junto com duas outras feministas acadêmicas de universidades dos Estados Unidos, ${ }^{11}$ um manifesto chamado "Feminismo para os 99\%: Um manifesto" onde estabelecem 11 teses. De uma forma geral, estas teses decretam a falência do feminismo liberal e o surgimento de um novo feminismo, no qual a greve de 100.000 mulheres na Polônia em 2016 aparece como marco:

${ }^{11}$ As coautoras do manifesto são: Cinzia Arruzza, italiana professora da New School for Social Reserach e Thihi Bhattacharya, indiana, professora da Universidade de Purdue, Indiana, Estados Unidos. 
este feminismo se constitui como antagônico ao capitalismo. A tese quatro é especialmente esclarecedora da posição teórica militante destas três acadêmicas: "Vivemos uma crise da sociedade como um todo - e sua causa originária é o capitalismo" (Fraser et.al., 2019, posição. 362). Descrevem a crise do capitalismo nas últimas quatro décadas de neoliberalismo, afirmando que em certos momentos o próprio capitalismo, para sobreviver, necessita destruir as condições que lhe possibilitam sobrevivência. Afirmam: "a crise que enfrentamos ameaça o que conhecemos por vida”. Após levantarem várias soluções paliativas, perguntam-se:

Ou será que um levante em massa contra o capital será finalmente o "ato pelo qual a raça humana, viajando em um trem desgovernado aciona a parada de emergência?” Neste caso, será que as feministas estarão na dianteira desse levante?

Se pudermos opinar a esse respeito, a resposta à última pergunta será "sim”. (Fraser et.al., 2019, posição.406).

As autoras não explicam como se organizarão para combater e vencer o capitalismo, mas isto é apenas um manifesto, um ato político, e minha exigência pode ser fora de lugar e desmobilizadora. A fragilidade do manifesto não está aí, mas na argumentação, que se repete ao longo do documento, de que a origem da opressão está no capitalismo, inclusive, a violência de gênero é reduzida às relações capitalistas. Daí, uma conclusão falaciosamente lógica, de que o fim do capitalismo envolverá o fim de toda a opressão sobre a mulher. A tese oito afirma que "o capitalismo nasceu da violência racista e colonial e que o feminismo 99\% é antirracista e anti imperialista”(...) permite ver com maior clareza a perspectiva reducionista do manifesto. É verdade que o capitalismo se desenvolve a partir de seu avanço colonial, da escravização de africanos e da destruição das culturas originárias do continente americano. Mas é verdade também que tanto nas diversas regiões africanas de onde foram arrancadas populações para se tornarem escravas, como nas culturas autóctones do continente americano haviam relações de poder que constituíam aquelas sociedades. O capitalismo, por vezes, aparece no texto como a maçã mordida por Eva, que acabou com uma vida idílica desfrutada pela humanidade.

Também parece razoável incorporar à análise das relações de poder que constituem as sociedades da modernidade, hierarquias pré-capitalistas que ordenavam a sociedade aristocráticas, não burguesas, assim como, o peso fundamental do poder da Igreja no sistema de dominação no feudalismo. Talvez por força das condições atuais do neoliberalismo que está se realizando através de projetos políticos de extrema direita, as teses do Manifesto estão mais próximas de Saffioti do que de toda a produção teórica anterior da própria Fraser.

\section{A PROPÓSITO DE UMA PERSPEC- TIVA PÓS-ESTRUTURALISTA}

Heleieth Iara Bongiovani Saffioti, cujo livro "A Mulher na Sociedade de Classes" é o mote deste artigo, não se autodenominava feminista quando o escreveu, nem acreditava em luta das mulheres a não ser como subsidiária da luta de classes liderada pelo proletariado. Quando me deparo, na atualidade, com uma enorme diversidade no interior do feminismo, me pergunto se não estariam todos dando razão a Saffiotti. O que afinal existe de comum em todos estes movimentos e designações que permite que eles sejam designados ou auto designados de feminismo?

Não se está aqui negando que existam diferentes feminismos, nem tampouco que houve uma hegemonia de um feminismo branco, acadêmico, predominantemente heterossexual, mesmo que nem sempre liberal, no século 20. Estou, sim, buscando o core, aquilo que, apesar das múltiplas diferenças, permita que sejam chamados todos da mesma maneira. O que eles têm em comum? A possível resposta a esta pergunta seria a luta contra a 
opressão das mulheres. Mas esta resposta é suficiente para definir o feminismo? Para que ela fosse suficiente teríamos de responder: quem oprime as mulheres? Parece que a resposta a esta pergunta obedece a uma curiosa trajetória. Para Saffiotti, não há dúvida de que quem oprime as mulheres é o capitalismo e que a forma de lutar contra ele é através da luta de classes. É o proletariado assexuado, no texto de Saffioti, que libertará as mulheres. Há uma estrutura lógica na sua tese, na qual reconhece a dominação das mulheres através das classes, só a luta de classes superará o capitalismo, e libertará a mulher. As feministas marxistas da década de 1980 tiveram uma leitura distinta da condição da opressão, também identificaram a divisão sexual do trabalho com básica no capitalismo como fundamental para entendê-la, mas introduziram um conceito importante, o patriarcado. Ou seja: as relações de poder não se esgotam nas classes, mas se combinam com as relações de poder entre os sexos onde os homens têm poder sobre a mulheres, redefinem o patriarcado em relação à ideia do pater poder, o alastrando para um poder masculino, que também organiza a sociedade e que se combina com o capitalismo.

O capitalismo é visto de forma diversa entre as feministas: ele pode alijar a mulheres do mercado de trabalho ou colocá-las em trabalhos considerados inferiores. Para outras, entretanto, o capitalismo não é essencialmente ণิ opressor das mulheres, não necessita obriga- toriamente desta opressão para se reproduzir, visto que esta opressão está combinada ao patriarcado. Talvez tenha sido este o momento em que o feminismo tenha tido sua definição menos problemática, na medida em que era definido por uma relação de poder entre os sexos, onde o masculino se colocava como o dominante. Isto não impediu que houvesse profundas cisões entre diferentes variantes do feminismo, desde as liberais até as radicais, passando pelas socialistas e marxistas.

Esta trajetória dá uma guinada a partir do feminismo decolonial e do feminismo ne- omarxista exemplificado no "Feminismo para 99\% - um manifesto", que se aproxima muito de Saffioti, na medida em que o elemento antagônico que constitui o feminismo praticamente desaparece da literatura. O antagônico da dominação das mulheres é o poder colonial e o capitalismo: na verdade, nos textos decoloniais, estas duas categorias funcionam como sinônimo, portanto, novamente o feminismo perde sua concretude como espaço de luta, na medida em que a luta contra o capitalismo não pode ser reduzida a uma luta contra a opressão da mulheres, mesmo que as três autoras do "Manifesto", de uma forma bastante militante, afirmem que o feminismo terá a liderança desta luta.

À guisa de conclusão, gostaria de contra argumentar, no sentido de reafirmar a independência e concretude da luta feminista. Já se disse que não haverá luta contra o capitalismo se ela não for feminista, o que me parece absolutamente correto. Entretanto, isto difere do argumento: a opressão das mulheres tem origem no capitalismo e se esgotará com seu fim, e que a luta será liderada pelo feminismo. Defenderei aqui duas ideias: a primeira, da irredutibilidade da opressão de gênero, isto é, a luta contra a opressão de gênero é uma luta que tem na sua escrita a luta contra o poder dos homens sobre as mulheres, no conjunto das relações das sociedade, quer sejam elas relações de trabalho, nas relações políticas, nos partidos políticos de todo o espectro ideológico, nas relações afetivas, no âmbito da cultura, das artes e das religiões. Esta opressão está para mais além do modo de produção, está instaurada nos corpos, e na possibilidade destes corpos sobreviverem ou não. A segunda ideia é a de que nenhuma opressão se esgota em si mesma, ela não é uma categoria fechada, da mesma forma que não se confunde completamente com nenhuma outra.

A materialidade do corpo feminino não pode ser subsumida a qualquer outra luta e está presente entre mulheres de todas as classes, de todas as etnias, de todas as religiões, do Sul e do Norte. É nesta materialidade que se 
inscreve a opressão: no corpo frágil ou forte; no corpo maternal; no corpo objeto de violência; no corpo objeto de estupro; no corpo explorado no trabalho; no corpo escravizado; no corpo indígena, negro, criança, velho, jovem. Estes corpos sofrem violência e opressão de formas distintas, mas no ato de uma mulher ser estuprada - no Central Park, em Nova York, em Moscou, no Rio de janeiro, em Nairobi, em Pequim, ou nas mais diversas situações de guerra ao redor do mundo - sempre haverá um corpo de mulher e um estuprador. É sobre este corpo que autoridades religiosas, políticas, econômicas decidem sobre a autonomia da mulher, determinando seu direito de ir e vir, sua posição no mercado trabalho, sua forma de vestir, intervindo em seu próprio corpo, permitindo ou não o aborto. Ou obrigando mutilações que se estendem da circuncisão feminina em culturas africanas às cirurgias plásticas deformantes para aumentar ou diminuir partes do corpo para sustentar a indústria da moda e de cosméticos no chamado Ocidente. Dando suporte a cada um destes atos existe um corpo de mulher. Um corpo marcado pelo poder do outro, que pode ser capitalista, pode ser socialista, pode ser religioso, pode ser branco, pode ser burguês: o outro, e este outro é homem, é o poder dos homens, que está no capitalismo, no socialismo, nas igrejas, nas culturas. E é sobre isto que trata o feminismo.

A segunda tese aponta para a incompletude de todas as lutas. ${ }^{12}$ Esta incompletude permite uma dependência virtuosa, que nega o relativismo irresponsável. A incompletude das lutas contra a opressão, contra o poder discricionário do outro, está impregnada da luta por igualdade e liberdade, que extrapola as lutas particulares. Estas lutas antecedem cada luta e as possibilitam. E como a opressão não se esgota em cada luta, ela permite que as lutas se articulem contra o opressor. Aqui há duas varian-

${ }^{12}$ A questão da incompletude das lutas e a capacidade de articulação entre elas foi vastamente desenvolvida nas obras de Ernesto Laclau e Chantal Mouffe, cujo o livro inaugural "Hegemonia e Estratégia Socialista foi publicado em 1988. tes a serem tomadas em consideração e que são relevantes para meu argumento. Uma é a articulação entre as diversas possibilidades do feminismo, outra é a articulação entre feminismo e outras lutas. Mas, há ainda uma pergunta anterior: podemos ainda chamar de feministas os movimentos que não podem se articular? A resposta parece ser positiva, e está na dependência do polo antagônico contra o qual a luta se estabelece. Pode-se chamar de feminista um movimento feminista liberal que luta por igualdade de oportunidades de trabalho no mundo capitalista do Norte Global? Ou um movimento feminista de mulheres islâmicas que lutam por serem respeitadas no limite do Corão? Sim, são feministas porque tanto no mundo do trabalho capitalista como no mundo do islamismo, estas mulheres estão estabelecendo como polo antagônico de luta o poder dos homens. Isto, no entanto, não torna viável per se uma articulação entre estes dois movimentos, mas também não há nenhum impedimento essencial. Vejamos um exemplo: em uma campanha mundial contra o estupro e assédio sexual como o \# metoo. é possível pensar em uma articulação internacional de mulheres de diferentes classes, etnias, culturas, religiões. Já em uma luta anticapitalista, feministas liberais estadunidenses podem abrir mão do feminismo para defender o capitalismo.

Se todos os movimentos não são articuláveis entre si, em todas as causas, cada um deles não pode se encapsular, sob pena de perder sua identidade feminista, daí que há uma larga avenida para articulações. O movimento feminista que não vê possibilidade de articulação com nenhum outro, não é feminista, pode ser no máximo estrategicamente feminista, em dados momentos. A segunda tese alastra esta capacidade de articulação: se a opressão não é somente contra a mulheres, mas há um conjunto de opressões que podem ser articuladas, parece evidente que a luta anticapitalista tem de ser feminista, mas também antirracista, anticlassista , antihomofóbica, antinacionalista. Ou seja, o pós-capitalismo, tenha o formato 
que tiver, não pode ser misógino, racista, homofóbico, xenófobo. Se o capitalismo não tem o monopólio destas opressões, a luta contra cada uma delas deve estar presente em todas as outras, e o pós-capitalismo não as rearticulará quando for necessário. Daí que não se trata de feministas lutando junto as classes populares machistas. Não se trata de aliança estratégica, mas de incorporação real da luta do outro. Trata-se de um feminismo antirracista, antihomofóbico, anti classista, lutando junto com um movimento negro, feminista, antihomofóbico e anticlassista, e com um partido revolucionário, feminista, antirracista e antihomofóbico. É um momento onde nenhum movimento perde totalmente sua identidade, mas incorpora a identidade do outro em uma luta contra a dominação capitalista. Quem terá a liderança, quem será o significante vazio que incorporará todos os outros, só é possível saber no decorrer da luta. Não há uma liderança essencial, substituir a classe proletária pelas mulheres a priori não passa de um wish fulthinking.

No cenário do fim da segunda década do século 21, quando um capitalismo neoliberal dá claros sinais de que não conseguirá sobreviver nos parâmetros dados pelo regime democrático, ameaçando os direitos políticos e sociais conquistados ao longo de um século e, principalmente, investindo com violência e criminalizando os movimentos sociais, dentre eles o feminista, o livro inaugural de Heleieth จิ Saffioti se reatualiza, por ter trazido o capitao lismo para o centro da discussão da opressão \& das mulheres.

Recebido para publicação em 20 de julho de 2020 Aceito em 16 de novembro de 2020

\section{REFERÊNCIAS}

BALLESTRIN, L . Feminismos Subalternos. Estudos Feministas, Florianópolis, 25(3): 530, setembrodezembro/2017,p. 1035-1054.

BARRETT, M. Women's Opression today - problems in marxist feminist analysis. London: Verso, 1980, 269 p.
FRASER, N. Justice Interruptus, critical reflections on the "postsoicalist"condition. New York: Routledge,1977.

Social Justice in the Age of Identty Politics Redistribution, Recognition and Participation. In: FRASER, N.; HONNETH, A. Redistribution or Recognition -a political-philophofical exchange. London: Verso, 2003, $276 \mathrm{p}$.

FRASER, N. et. al. Feminismo para os 99\% Um Manifesto. São Paulo: Boitempo, 2019.

HARDING, S. What is the Real Material Base of Patriarchy and Capital? In: SARGENT, L. The Unhappy Marriage of Marxism and Feminism. London: Pluto Press 1981. p.135164.

HARTMANN, H. The Unhappy Marriage of Marxism and Feminism: towards a more progressive union. In: SARGENT, L. The Unhappy Marriage of Marxism and Feminism. London: Pluto Press, 1981, p.1-43.

LACLAU, E; MOUFFE , C. Socialismo e Estratégia socialista - por uma política democrática radical. São Paulo: Intermeios, 2015. 286 p.

PINTO,C. Uma história do Feminismo. São Paulo: Perseu Abramo, 2003. 119p.

SAFFIOTI, H. A Mulher na Sociedade de Classes - Mito Realidade. São Paulo: Expressão Popular, 2013. 527 p.

SARGENT, L. (ed) The Unhappy Marriage of Marxism and Feminism. London: Pluto Press 1981. 373p.

YOUNG, I. Beyond the Unhappy Marriage: A critique of the dual Systems Theory. In: SARGENT, L. (ed) The Unhappy Marriage of Marxism and Feminism. London: Pluto Press 1981. p.43- 69. 


\section{SAFFIOTI REVISITED: the topicality of the confrontation between feminism and marxism}

\section{Céli Regina Jardim Pinto}

The article departs from the theses of Heleieth Saffioti's book "The woman in the Class Society" and analyzes the centrality of capitalism in the oppression of women and the consequences of this in the feminist theoretical scholarship that defends the overcoming of capitalism as essential for women's liberation. It is divided into 4 parts: the first exposes Saffioti's theses subsidized by an orthodox Marxism that does not recognize the feminist struggle; the second discusses the encounter between Marxism and feminism in the 1980s; the third part discusses some of Nancy Fraser's theses, showing her trajectory from an eclectic to a neo-Marxist stance; finally, in the last part, the issues discussed are examined from a post structuralist perspective.

Keywords: Saffioti. Docial classes. Women. Mots-clés: Saffioti. Classes sociales. Femmes. Feminism. Female work.

\section{SAFFIOTI REVISITED: la confrontation actuelle entre féminisme et capitalisme}

Céli Regina Jardim Pinto

Larticle part des thèses du livre d'Heleieth Saffioti "La femme dans la société de classe" et analyse la centralité du capitalisme dans l'oppression des femmes et les conséquences de cela dans la production théorique féministe qui défend le dépassement du capitalisme comme essentiel pour la libération des femmes. Il est divisé en 4 parties: dans la première, le texte expose les thèses de Saffioti cultivés par un marxisme orthodoxe qui ne reconnaît pas la lutte féministe; dans le second, il évoque la rencontre entre le marxisme et le féminisme dans les années 1980; dans la troisième partie, le texte discute certaines des thèses de Nancy Fraser, montrant sa trajectoire d'une position éclectique à une néo-marxiste; enfin, dans la dernière partie, les questions abordées dans les trois premières sont traitées dans une perspective post-structuraliste.

Féminisme. Travail féminin.

Céli Regina Jardim Pinto - Professora Emérita da Universidade Federal do Rio Grande do Sul. Atualmente é professora Titular aposentada da Universidade Federal do Rio Grande do Sul atuando como docente permanente no Programa de Pós Graduação em História desta mesma universidade. Doutora em Ciência Política na University of Essex na Inglaterra. Pesquisadora 1b do CNPq. Foi visiting Scholar na UCLA, na Universidade Livre de Berlin e na Universidade de Oxford. Foi visiting professor na UCLA e na UDELAR (Uruguai) Proferiu palestras na Universidade de Princeton, na UCLA na London School of Economic, na Universidade de Oxford. Sua produção cientítifica, expressa em livros, capítulos de livros e artigos trata de Teoria Política com ênfase em teoria da democracia e teoria feminista. Também atua na área de História do Brasil República nos seguintes temas: politica brasileira, feminismo, participação politica. 
